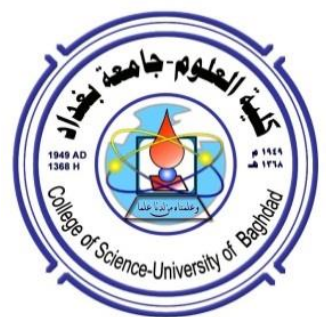

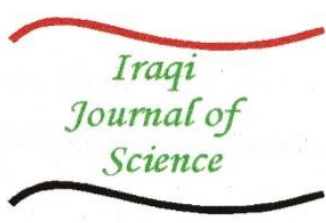

ISSN: 0067-2904

\title{
Green Synthesis of Nickel Nanoparticles and their Application of Removal of Aliphatic Hydrocarbons from Crude Oil
}

\author{
Ahmed Makki Sadaa ${ }^{1}$, Zainab Taha Al Abdullah ${ }^{2}$ \\ ${ }^{I}$ Basra Education Directorate, Ministry of Education, Basra, Iraq \\ ${ }^{2}$ Chemistry, College of Education for Pure Sciences, University of Basra, Basra, Iraq
}

Received: $16 / 1 / 2021$

Accepted: 20/6/2021

\begin{abstract}
Nickel nanoparticles (Ni-nanoparticles) were incorporated as an antecedent utilizing nickel acetate and as a reducing agent, extraction plantApiumgraveolens. The reason fo choosing this plant over many other is because it is easily accessible, carries many antioxidants, non-toxic, and there are no dangerous residues and stabilizing agent at $60^{\circ} \mathrm{C}$ under stirrer. The progress of the reaction was monitored by observing a change in color of the obtained solution. The UV-Vis utilized to screen the development of Ni-nanoparticles inside a surface plasmon band (SPB) at $275 \mathrm{~nm}$ gives a phantom mark appropriate to the arrangement of nanoparticles. Examining the electron microscope (SEM) photos showed the Ni-nanoparticles to be of cubic shape with sizes in te range of $(6-45 \mathrm{~nm})$. GC-MS s spectra were utilized to show the debasement when the expansion of nickel nanoparticles. The most noteworthy accessibility of aliphatic mixes at the hour of $(1.3,1.46,1.62$, 12.04) min. In the interim after the expansion of nanoparticle, the outcomes show a high bounty at $(1.29,2.1) \mathrm{min}$. The importance of this research lies in the possibility of breaking large organic compounds into simpler compounds, as the presence of large organic compounds with high molecular weights leads to pollution of sea and ocean waters when poured into it as a result of sea transport.
\end{abstract}

Keywords: degradation; Nickel Nanoparticle; water pollutants, GC-mass.

\section{التخليق الأخضر لجسيمات النيكل النانوية وتطبيقها في إزالة الهيدروكربونات الأليفاتية من النفط الخام}

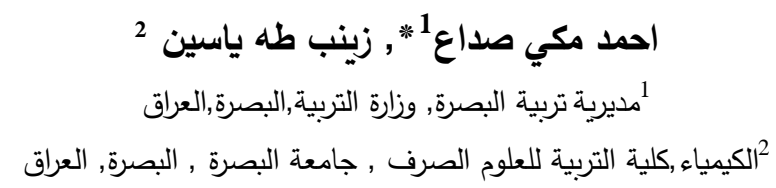

الخلاصة

جسيمات النيكل النانوية (Ni-nanoparticles) مدمجة كسابق باستخدام أسيتات النيكل وكعامل مختزل ،

استخراج نباتApium Gravolens، والسبب في اختيارنا هذا النبات على العديد من الأنواع الأخرى لأنه

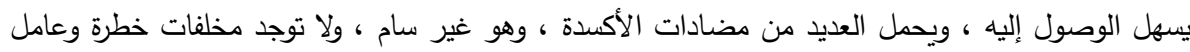

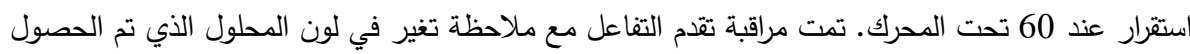

عليه. تُستخدم الأشعة فوق البنفجية - المرئية لفحص تطور جزيئات النيكل النانوية داخل نطاق سطحي من فن فئن

"Email: al.mhamedmaki@gmail.com 


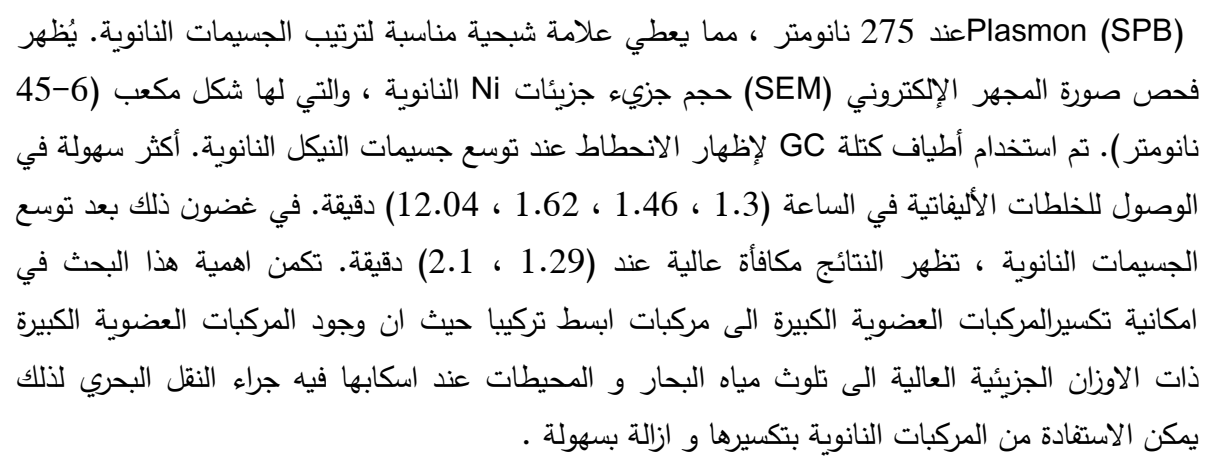

\section{Introduction}

One of the most real organic issues today is the corrupting of the climate, especially water bowls, with oil and oil-based wares. The critical endeavours in understanding this issue consolidate rule, limitation, and slowing down of the effects from the release of water bowls and the oceans . According to data presented by the US National Academy of Sciences, the yearly volume of oil and oil things released by different sources into the seas and oceans is about 20 million tons [1]. The explanations behind tainting are most usually oil and oil substance spills achieved by enormous hauler or submarine pipeline crashes, similar to the ocean oil stages and oil treatment offices. The over the edge emptying of liquid waste into the sea is one a greater amount of the marine business' major environmental issues. Starting late, transport firms have been enthusiastically fined for the evacuation of the spread of smooth wastewater. Empowers, oils, chemicals, oils, solvents, rusts, paints, insurance content and a w may be normal pollutions and a wide collection of various materials.

A couple of approaches for the status of metal nanoparticles have been developed, for instance, photocatalytic decline, nonchemical framework, polyol measure, and scaled-down emulsion system for dissolvable extraction diminishing and alcohol reduction[2]. The preparation of certain metal nanoparticles, for instance, nickel, copper, and iron are generally inconvenient among the different kinds of metal nanoparticles because they are immediately oxidized. Nickel is a huge advancement metal and nickel nanoparticles have a wide arrangement of jobs in the fields of waste debasement and decline impulses, and common activity [2]. The association of $\mathrm{Ni}$ nanoparticles has, for all of these reasons, drawing the mind-blowing thought of various specialists for its association. Different techniques for the mix of nickel nanoparticles [3-20] have been set up, an enormous number of which are followed by an irksome cycle for the separation of nanoparticles, extreme conditions of reaction, and the use of costly reagents, and there is potential to advance new nickel nanoparticles mix methods.

To be dynamic in redox works out, phenolic blends, for instance, tannins, flavonoids, and phenolic acids are thought of. Because of their redox works out, phenolic heightens, fill in as hydrogen supporters, promoter removal, singlet oxygen quenchers,

Furthermore, steel chelating agents [21]. There are various wellsprings of phenolic blends inside plant isolates. They are particularly open blends and think about redox responses. The presence inside the plant concentrate of general phenolic blends may be liable for the diminishing of steel particles and for the methodology of the different metal nanoparticles [22]. In these tests, the Apiumgraveolens remove plant was used in the association of nickel nanoparticles as a diminishing authority. ApiumGravolens is the clarification we pick this flavour over various species since it is speedily open, passes on various disease counteraction operators, is non-noxious, and there are no harmful developments. The plant isolates are completely used for metallic nanoparticle association, as they are effectively open, secure, and strong and feature an expansive sort of metabolites (phytochemicals) that are a useful resource 
in the abatement of metal particles faster than the microorganism's intervened association [23].

In this research, Nickel nanoparticles used in the procedure of degradation of the aliphatic hydrocarbon compounds of crude oil were applied after the separation of the aromatic compounds from the aliphatic. The separation process was followed by the degradation of aliphatic hydrocarbons using Ni-nanoparticles a GC-MS spectrum.

\section{Experimental}

\subsection{Materials}

Nickel acetate $\mathrm{Ni}(\mathrm{CH} 3 \mathrm{COO})_{2}$ was purchased from Merck (Darmstadt, Germany). All the solutions were prepared with double-distilled water.

\subsection{Synthesis of nickel nanoparticles}

To prepare the Apium graveolens extract, $125 \mathrm{~g}$ of the plant was mixed with 1 litre of double distilled water and heated to boiling point for half an hour. The resulted solution was filtered and the leachate was taken. This was re-filtered using filter paper, and $100 \mathrm{~mL}$ of it was added to $0.1 \mathrm{~g}$ of nickel acetate , then heated at $60^{\circ} \mathrm{C}$ for half an hour until the color was changed to light green .

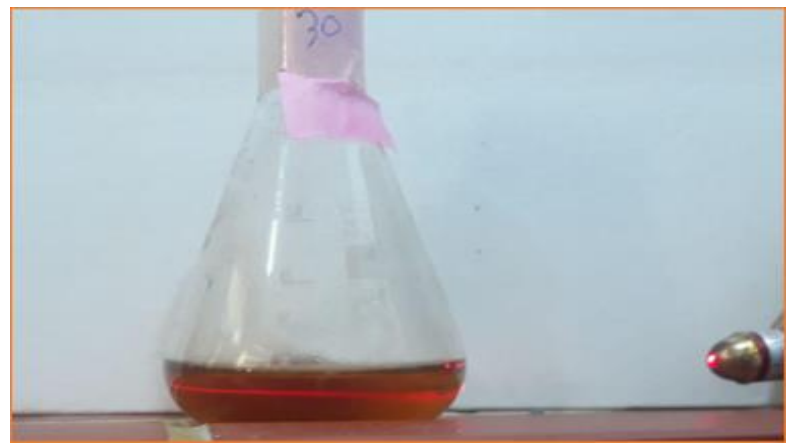

Figure 1-optical photograph show laser beam path due to the Tindall effect in Nickel nanoparticles solution.

\subsection{The process of separating crude oil into aromatics and aliphatic:}

$0.0741 \mathrm{~g}$ of crude oil was dissolved in $6 \mathrm{~mL}$ hexane, then placed in the pre-prepared glass column of glass wool, $5 \mathrm{~g}$ of silica gel, $5 \mathrm{ml}$ of alumina and $2.5 \mathrm{ml}$ of anhydrous sodium sulfate. The separation of aromatic compounds from aliphatic was achieved through the addition of benzene. GC-mass was measured by taking a quantity of $(0.07 \mathrm{~g})$ isolated electrolytes in $6 \mathrm{~mL}$ of hexane as a solvent. The same method was repeated but with the addition of $0.18 \mathrm{~g}$ of the prepared nickel nanoparticles.

\subsubsection{Crude Oil degradation by Nickel nanoparticles:}

Firstly, the crude oil was extracted using column chromatography provided with alumina, silica and hexane used as a solvent for the mobile phase. Secondly, the aliphatic hydrocarbons were collected and analysed with GC-MS , to get spectra before and after the addition of (0.5) $\mathrm{g}$ of nickel nanoparticles for 3 hours under 30 watts LED illumination. . The aliphatic hydrocarbons were extracted in hexane. $0.1 \mathrm{~g}$ of nickel nanoparticles was collected from aqueous solution through centrifugation which was added to $0.05 \mathrm{~g}$ from aliphatic hydrocarbons for 3 hours with 30 watts LED illumination for degradation. Nickel nanoparticles were used for degradation of total hydrocarbon in Basra crude oil (IRAQ). The degradation was managed using the GC-MS technique.

\subsubsection{Characterization Method}

The prepared Ni-nanoparticles were monitored by UV-Vis spectroscopy in the wavelength range from 300-700 $\mathrm{nm}$. SEM imaged Ni-nanoparticles and it was applied for degradation of aliphatic hydrocarbons from crude oil in polluted area in Basra. The degradation was examined using GC-MS spectra. 


\section{Results and Discussion}

\subsection{UV-Vis spectroscopy of Ni- nanoparticles}

$\mathrm{Ni}$-nanoparticles solutions were studied by UV-Vis spectroscopy to detect plasmon spectrum . The reduction reaction of $\mathrm{Ni}^{++}$ions to $\mathrm{Ni}^{0}$ was monitored by recording $\mathrm{UV}-\mathrm{V}$ is spectrum of Ni- nanoparticles $(1.0 \mathrm{~mL})$ after dilution with $3.0 \mathrm{~mL}$ deionized water (Figure 2). The absorbance peaks appeared at regions $(200-450 \mathrm{~nm})$ due to an excitation of surface vibrations in $\mathrm{Ni}$ - nanoparticles solution. The maximum absorbance at $275 \mathrm{~nm}$ is attributed to surface plasmon band (SPB) due to the formation of Ni- nanoparticles.

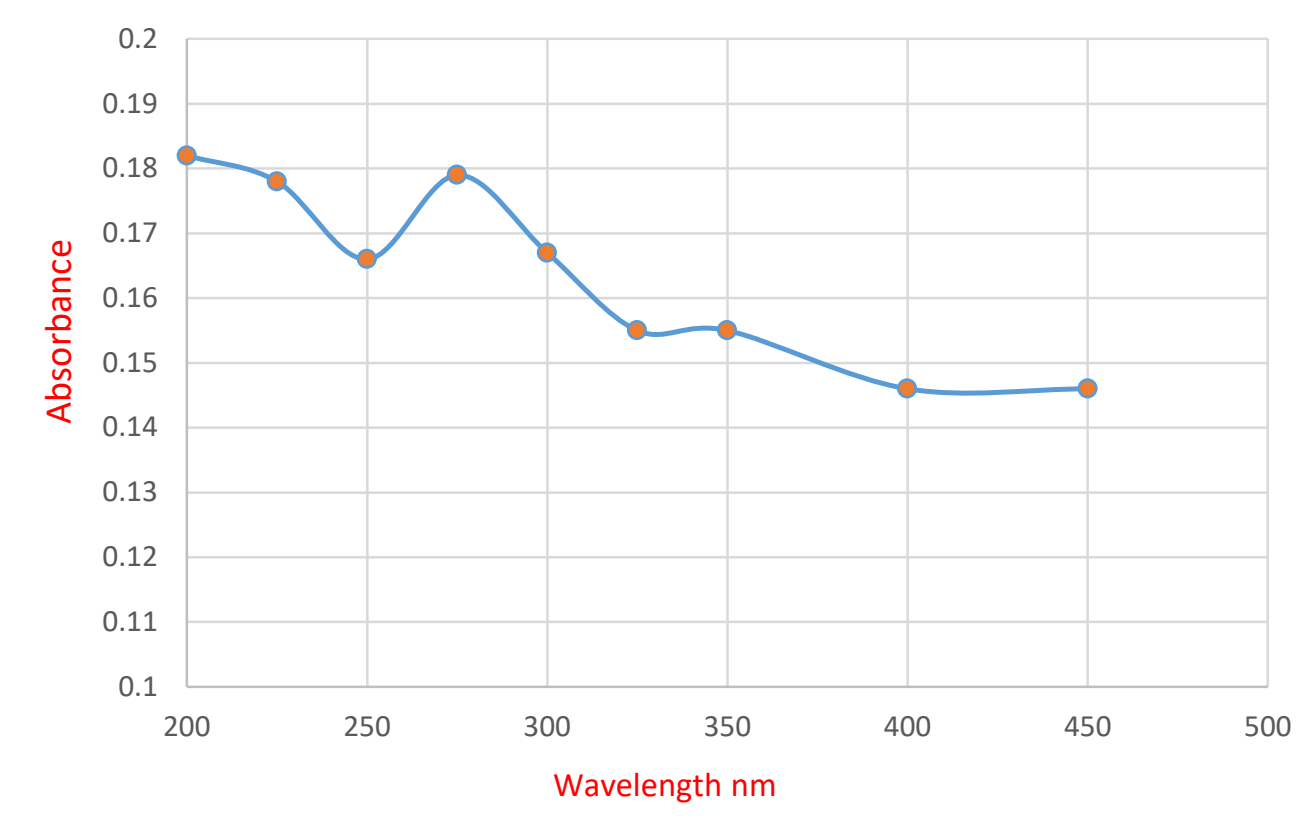

Figure 2-UV-iVsible absorption spectrum of Ni-NPs

\subsection{Scanning electron microscopy (SEM)}

The particle size of Ni- nanoparticles was determined by SEM images. The image of the Ninanoparticles exhibited a clear separation. These nanoparticles also showed uniform style in the solution. The Ni-nanoparticles were of cubic shape with sizes in the range of 20-100 nm.

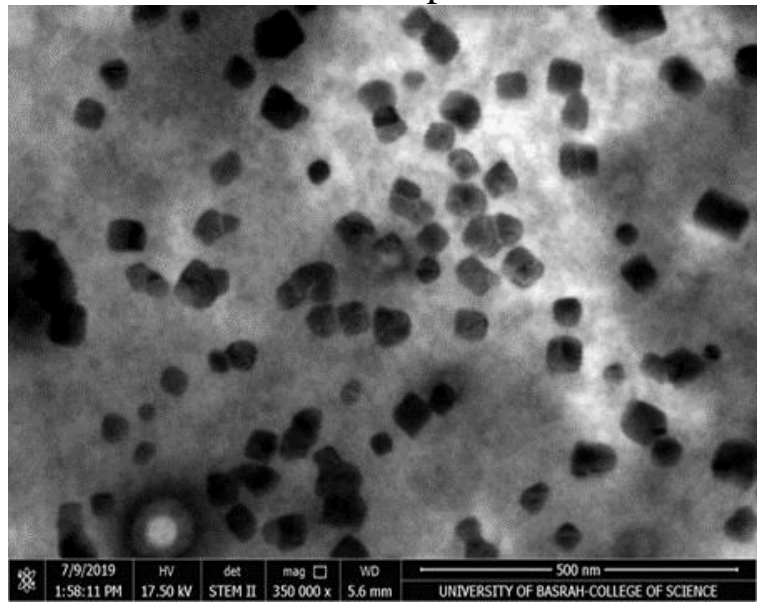

\section{1}

Figure 3-(SEM) images

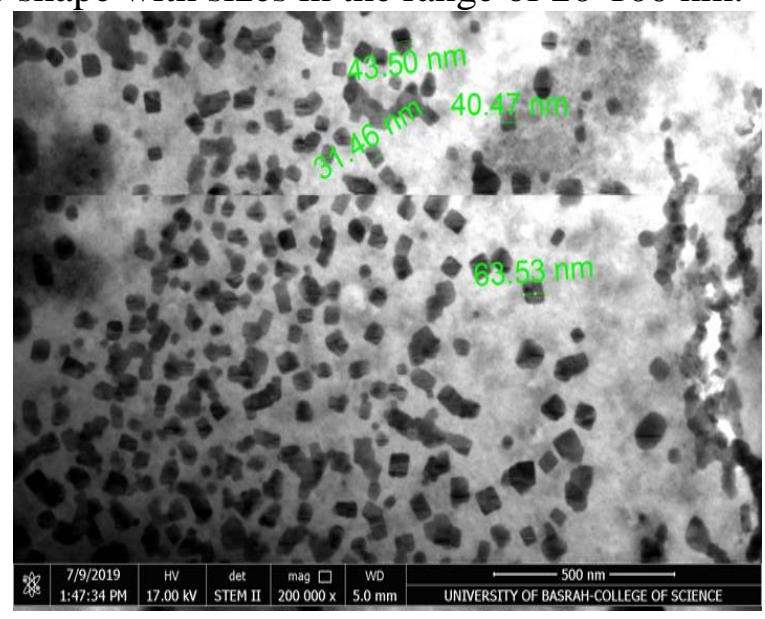

2

\subsection{Degradation of aliphatic hydrocarbons using Ni-nanoparticles}


A GC- chromatogram represents the relationship between time (min) and abundance. Figure 4 represents the chromatogram before the addition of Ni-nanoparticles. The peaks observed are at the retention time.

Figure 5 shows the chromatogram after the addition of Ni-nanoparticles. Characterizes the GC spectrum of aliphatic hydrocarbons separated from Iraqi crude oil after the addition of Ninanoparticles. The presence of peaks at the time of retention can be seen in the graph:( respectively). Comparing these, the disappearance of some peaks and the emergence of new peaks can be noted. In addition the decrease in abundance can also be noted, indicating the breakage of some vehicles and the emergence of new organic molecules. Table 1 and Table 2 list the mass spectra analysis at the time of retention of the aliphatic hydrocarbons before and after degradation, respectively[24].

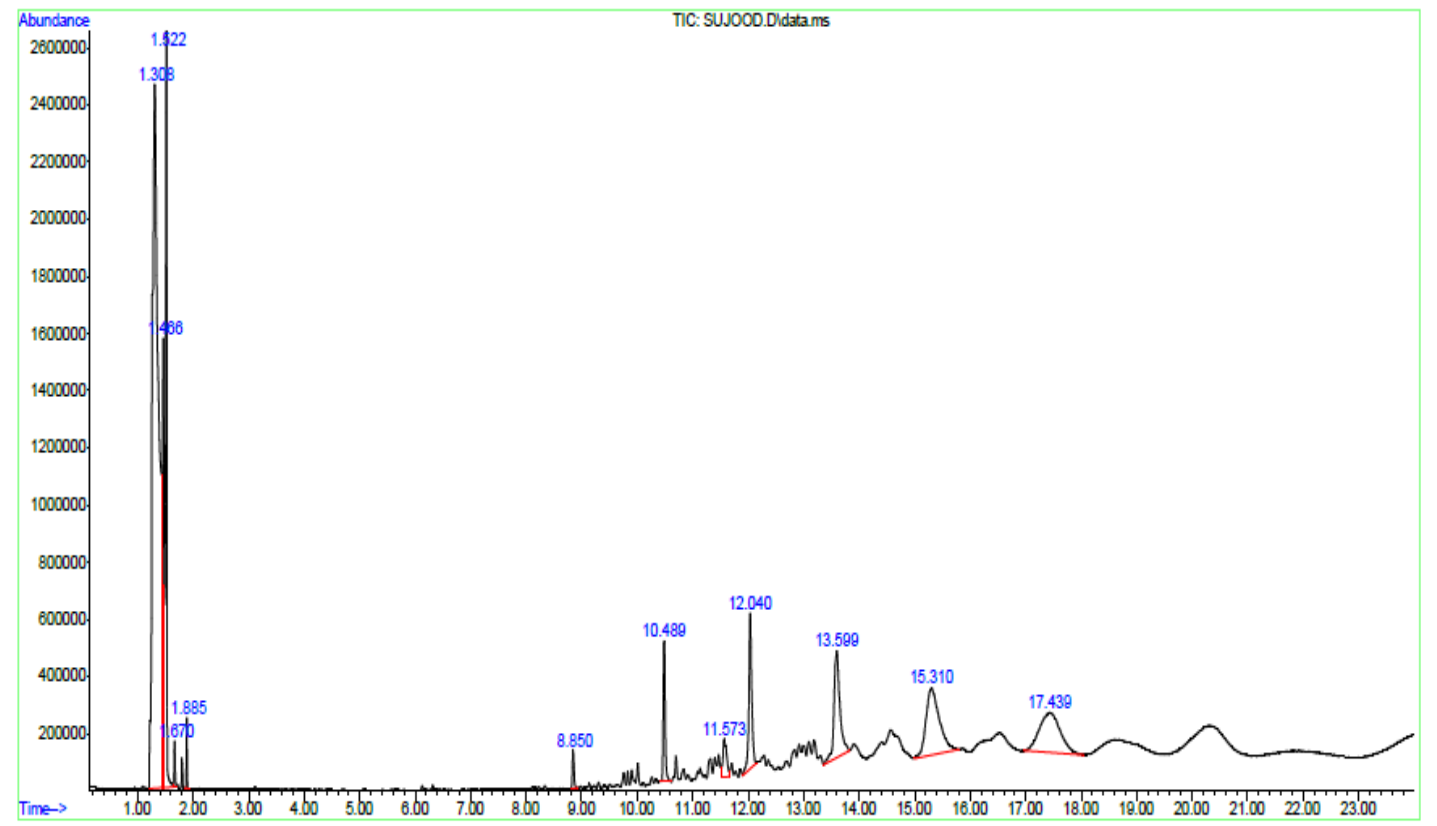

Figure 4-GC- Chromatogram of the aliphatic hydrocarbons in Iraqi crude oil before the addition of Ni- nanoparticles.

Table 1- mass spectra of aliphatic crude oil before addition of Ni- nanoparticles

\begin{tabular}{cccccc}
\hline Peak no. & Organic compounds & $\%$ & $\mathrm{M} / \mathrm{Z}$ & Base peak & $\mathrm{RT}(\mathrm{min})$ \\
\hline .1 & 3-methyl- pentane & 13.2 & 86 & 57 & 1.3 \\
\hline .2 & 2-methyl butane & 25.8 & 72 & 43 & 1.46 \\
\hline .3 & Pentane & 2.47 & 72 & 43 & 1.46 \\
\hline .4 & Methyl - cyclo Pentane & 42.2 & 84 & 56 & 1.52 \\
\hline .5 & Ethyl cyclobutane & 21.7 & 84 & 56 & 1.52 \\
\hline .6 & Cyclohexane & 32.4 & 84 & 56 & 1.67 \\
\hline .7 & 2-methyl 1-pentene & 7.26 & 84 & 56 & 1.67 \\
\hline .8 & Heptane & 47.5 & 100 & 43 & 1.88 \\
\hline .9 & 3-methyl hexane & 32.6 & 100 & 43 & 1.88 \\
\hline
\end{tabular}




\begin{tabular}{cccccc}
\hline .10 & Undecane & 25.1 & 156 & 57 & 8.8 \\
\hline .11 & Dodecane & 7.12 & 170 & 57 & 8.8 \\
\hline 12 & Tetradecane & 21.2 & 198 & 57 & 10.4 \\
\hline .13 & 1-octadecane sulphonyl chloride & 7.24 & 352 & 57 & 11.57 \\
\hline 14 & 6-methyl octadecane & 7.26 & 268 & 57 & 12.04 \\
\hline .15 & Nonadecane & 4.18 & 268 & 57 & 12.04 \\
\hline .16 & 2,6,10-trimethyl tetradecane & 19.4 & 212 & 57 & 13.5 \\
\hline .17 & Heptadecane & 3.66 & 240 & 57 & 13.5 \\
\hline .18 & 10-methyl- eicosane & 3.66 & 296 & 57 & 15.3 \\
\hline .19 & di-tert-dodecyl disulfide & 3.01 & 402 & 57 & 15.3 \\
\hline .20 & 1-chloro -octadecane & 7.18 & 288 & 57 & 17.4 \\
\hline
\end{tabular}

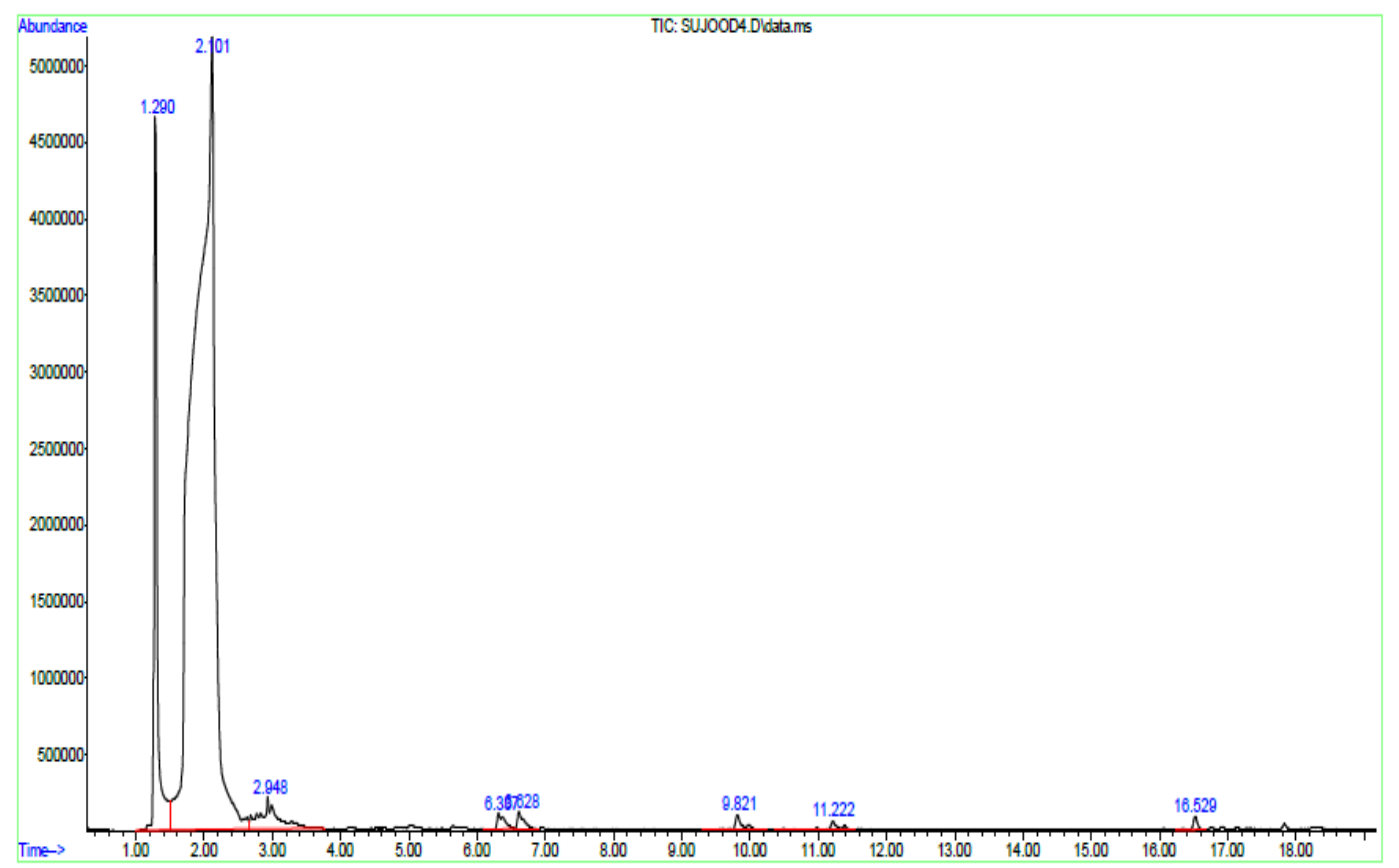

Figure 5-GC- Chromatogram spectra of the aliphatic hydrocarbons in Iraqi crude oil after addition of Ni-nanoparticles. 
Table 2-Results of GC.-MS. analysis of the saturated hydrocarbon fraction of condensate Musharraf's reservoir, the Artawi Field, Basra County after degradation by the nickel nanoparticles solution

\begin{tabular}{cccccc} 
Peak no. & Organic compounds & $\%$ & M/Z & Base peak & RT(min) \\
\hline 1. & Pentane, 2,4-dimethyl & 13.0 & 100 & 43 & 1.29 \\
\hline 2. & n-Hexane & 22.5 & 86 & 57 & 2.1 \\
\hline 3. & Pentane, 3-methyl & 14.1 & 86 & 57 & 2.1 \\
\hline 4. & Acetic acid, butoxyhydroxy-, butyl & 1.8 & 204 & 41 & 2.1 \\
\hline 5. & Hexane, 2,4-dimethyl & 4.92 & 114 & 43 & 2.94 \\
\hline 6. & Hydro peroxide, 1-ethylbutyl & 55.1 & 118 & 43 & 6.3 \\
\hline 7. & Oxirane, 2,2-dimethyl-3-propyl & 6.06 & 114 & 43,59 & 6.3 \\
\hline 8. & Hexane, 2-nitro & 3.91 & 131 & 43 & 6.3 \\
\hline 9. & Dodecane & 9.08 & 170 & 57 & 9.82 \\
\hline 10. & Dodecane, 2,6,10-trimethyl & 6.77 & 212 & 57,71 & 9.82 \\
\hline 11. & $2,6-$ Dimethyldecane & 6.24 & 170 & 43 & 9.82 \\
\hline 12. & Undecane & 7.17 & 156 & 57 & 11.22 \\
\hline 13. & Dodecane, 2,6,11-trimethyl & 9.09 & 212 & 57,71 & 16.52 \\
\hline 14. & Hexadecane, 2,6,11,15-tetramethyl & 6.78 & 282 & 57 & 16.52 \\
\hline 15. & Pentadecane & 6.25 & 212 & 57 & 16.5 \\
\hline
\end{tabular}

From Table 2 and Figure 4 , the analysis of the most important results of the GC-MS measurements showed that it was the highest availability of aliphatic compounds after degradation for $(1.29,2.1)$ min by the addition of nickel nanoparticles solution . The carriers were (n-Hexane, Pentane, 3-methyl-Pentane, 2, 4-dimethyl, n-Hexane, Pentane, 3-methyl, Acetic acid, butoxyhydroxy-, butyl ester). The results indicated the degradation of aliphatic compounds after the addition of nickel nanoparticle solution.

\section{Conclusion}

The emergence of surface plasmon resonance peak at $(275 \mathrm{~nm})$ provides a spectral signature of the formation of nanoparticles. The present work demonstrates an economical, simple, and fast method for preparing nanoparticles. Analysis of the SEM images of Ni-nanoparticles showed it to be of cubic shape with particles size in the range of (20-100) nm. These new results demonstrate that $\mathrm{Ni}$ nanoparticles were effective in the degradation of ores into simple hydrocarbons. The current work provides a promising method for releasing natural organic matter with Ni-Nanoparticles from water and sediments. Nickel nanoparticles can be used to create hybrid polymers and be used to remove crude oil contaminants. The results of this work demonstrate the ability of the nanoparticles to be patched as a photo catalyst for the decomposition of aliphatic hydrocarbons in Iraqi crude oil. The total procedure for the synthesis of nanoparticles by the wet method and their applications in the decomposition of different aliphatic hydrocarbons in the field of green chemistry with the least contamination in both the reaction and the product in the synthesis and in applications. 


\section{References}

[1] Murashev IA, Semanov GN. "Methods of testing and estimation of ability of some materials to sorb petroleum and petroleum products" Metodikaizpitanii Iotsenkasposobnostisorbtsiinefte produktovnekotoramimaterialamiTrudiy, CNIIMFA, vol. 237, pp. 43-50, 1978 (in Russian).

[2] Chen D and Hsieh C. "Synthesis of Nickel nanoparticles in aqueous cationic surfactant solutions". J Mater Chem, vol. 12, no. 8, pp. 2412-5, 2002.

[3] Zhang D.E. , Ni X.M., Zheng H.G., Li Y., Zhang X.J., Yang Z.P. "Synthesis of needle-like Nickel nanoparticles in water-in-oil micro emulsion". Mater Lett; vol. 59, no. 16, pp. 2011-4, 2005.

[4] Ying Z, Shengming J, Guanzhou Q., Min Y.,"Preparation of ultrafine Nickel powder by polyol method and its oxidation product". Mater Sci Eng B, vol. 122, no. 3, pp. 222-225, 2005.

[5] Wang H, Jiao X, Chen D. "Monodispersed Nickel nanoparticles with tunable phase and size: synthesis, characterization, and magnetic properties". J. Phys.Chem. C., vol. 112, no. 48, pp. 18793-7, 2008.

[6] Abu-Much R, Gedanken A., "Sonochemical synthesis under a magnetic field: fabrication of Nickel and cobalt particles and variation of their physical properties". Chemistry, vol. 14, no. 32, pp. 10115-22, 2008.

[7] Gafner SL, Gafner YY., "Analysis of gas-phase condensation of Nickel nanoparticles". J Exp. Theor.Phy., vol. 107, no. 4, pp. 712-22, 2008.

[8] S.J.Kim, B. Hoon Kim, M.C. Chung, H.G.Ahn, S.C. Kim, H. G. Kim, S.C. Jung, "The synthesis of Nickel nanoparticles by liquid phase plasma processing" J. Nanosci. Nanotechnol., vol. 13, no. 3, pp. 1997-2000, 2013.

[9] W. Xu, K. Y. Liew, H. Liu, T.Huang, C. Sun, Y. Zhao, "Microwave-assisted synthesis of Nickel nanoparticles". Mater Lett., vol. 62, no. (17-18), pp. 2571-3, 2008.

[10] Eluri R, Paul B., "Microwave assisted greener synthesis of Nickel nanoparticles using sodium hypophosphite". Mater. Lett., vol. 76, pp. 36-9, 2012.

[11] Adél Anna Ádám, Márton Szabados, Gábor Varga, Ádám Papp, Katalin Musza, Zoltán Kónya, Ákos Kukovecz, Pál Sipos, and István Pálinkó "Ultrasound-assisted hydrazine reduction method for the preparation of nickel nanoparticles, physicochemical characterization and catalytic application in Suzuki-Miyaura cross-coupling reaction" Nanomaterials, vol. 10, no. 4, pp. 632, 2020.

[12] Capek I. "Preparation of metal nanoparticles in water-in-oil (w/o) microemulsions". Adv Colloid Interface Sci., vol. 110, no. (1-2), pp. 49-74, 2004.

[13] Lu, J., Wang, J., Hassan, K. T., Talmantaite, A., Xiao, Z., Hunt, M. R., \&Šiller, L."Morphology control of nickel nanoparticles prepared in situ within silica aerogels produced by novel ambient pressure drying." Scientific Reports, vol. 10, no. (11743), pp. 1-9, 2020.

[14] Singh K., Kate K.H., Chilukuri V.V., Khanna P. K., "Glycerol mediated low temperature synthesis of Nickel nanoparticles by solution reduction method". J Nanosci Nanotechnol., vol. 11, no. 6, pp. 5131-6, 2011.

[15] Cordente, N., Respaud, M., Senocq, F., Casanove, M. J. Amiens, C., \& Chaudret, B., "Synthesis and magnetic properties of Nickel nanorods". Nano Lett., vol. 1, no. 10, pp. 565-8, 2001.

[16] J. Park, E. Kang, S. U. Son, H. M. Park, M. K. Lee, J. Kim, K. W. Kim, H.-J. Noh, J.-H. Park, C. J. BaeJ.-G. ParkTPark, J., Kang, E., Son, S. U., Park, H. M., Lee, M. K., Kim, J., \&Hyeon, T. "Monodisperse nanoparticles of $\mathrm{Ni}$ and $\mathrm{NiO}$ synthesis, characterization, self-assembled superlattices, and catalytic applications in the Suzuki coupling reaction". Advanced Materials, vol. 17, no. 4, pp. 429-434, 2005.

[17] Babu RS, Prabhu P, Narayanan SS. "Green synthesized Nickel nanoparticles modified electrode in ionic liquid medium and its application towards determination of biomolecules". Talanta, vol. 110, pp. 135-43, 2013.

[18] Mas, N., Hueso, J. L., Martinez, G., Madrid, A., Mallada,R., M. Carmen Ortega-Liebana Carlos Bueno-Alejo, Jesus Santamaria,"Laser-driven direct synthesis of carbon nanodots and application as sensitizers for visible-light photocatalysis". Carbon, vol. 156, pp. 453-462, 2020.

[19] Nasrollahzadeh M, \&. Sajadi S M, "Green synthesis of copper nanoparticles using Ginkgo biloba L. leaf extract and their catalytic activity for the Huisgen [3+2] cycloaddition of azides and alkynes at room temperature". J. Colloid Interface Sci., vol. 457, pp. 141-147, 2015. 
[20] Rice-Evans C, "Flavonoids and Isoflavones: absorption, metabolism and bioactivity". Free Rad. Biol. Med., vol. 36, no. 7, pp. 827-828.

[21] Abdel-Hameed, E. S. S., Bazaid, S. A., \& Sabra, A. N. A. "Protective effect of conocarpus erectus extracts on $\mathrm{CCl} 4$-induced chronic liver injury in mice". Glob J Pharmacol, vol. 7, no. 1, pp. 52-60, 2013.

[22] El-Sayed S, Bazaid S, Shohayeb M. Mortada M. El-Sayed\& El-Wakil EA "Phytochemical Studies and Evaluation of Antioxidant, Anticancer and Antimicrobial Properties of Conocarpus erectus L. Growing in Taif, Saudi Arabia”. European Journal of Medicinal Plants, vol. 2, no. 2, pp. 93-112, 2012.

[23] R. Khalighi Sheshdeh, K. Badii, S. Mohammadzadeh Reza, K.S., Mohammad, R.K.N., Khashayar, B., Soroush, M., "Evaluation of adsorption kinetics and equilibrium for the removal of benzene by modified Diatomite", Chem. Eng. Technol., vol. 36, no. 10, pp. 1713-1720, 2013.

[24] Ibrahim Ali Amar, Sawsan I. Faraj, Mabroukah Abdulqadir, Ihssin Abdalsamed, Fatima Altohami, Mohammed Samba, . "Oil Spill Removal from Water Surfaces using Zinc Ferrite Magnetic Nanoparticles as A Sorbent Material”. Iraqi Journal of Science, vol. 62, no. 3, pp.718728, 2021. 